\title{
EQUATIONS TRANSFORMED AND EXPANDED FOR A GENERAL STUDY OF ISOTROPIC PLATES WITH THE BOLLE - REISSNER THEORY AS A STARTING POINT
}

\author{
J. M. Martínez Valle ${ }^{1}$, T. Balcaza Bautista ${ }^{3}$, J.M. Martínez-Jiménez ${ }^{1}$, P. Martínez Jiménez ${ }^{2}$ \\ ${ }^{1}$ Department of Mechanics of Continuous Medium, Polytechnic School at the University of \\ Córdoba, Spain (jmvalle@uco.es)
}

${ }^{2}$ Department of Applied Physics, Polytechnic School at the University of Córdoba, Spain

${ }^{3}$ Department of Applied Mathematics, Polytechnic School at the University of Jaén, Spain

\begin{abstract}
Taking the Bolle - Reissner theory as a starting point, we have derived a system of differential equations of a general character which are applicable to the calculation of plates regardless of their thickness, freeing us from the thin/thick plate dilemma. It has the added advantages of not presenting any numerical instability problems when the calculation is approached through finite differences and of being able to benefit from the range of solutions and methodology at present being developed for thin plates if the resolution is attempted analytically.
\end{abstract}

Keywords: Thick Plates, Elasticity, Linear Calculation.

\section{INTRODUCTION}

On analyzing the current trend in plate study, it can be observed how out of seven papers on theoretical aspects of the analysis included by Voyiadjis \& Karamanllidis in "Advances in the Theory of Plates and Shells [8], four of them make a direct reference to thick plates, taking into account in them in one way or another the bases sustaining the theories originated by the contributions of Reissner (1945) [5], Bolle (1947) [2], Mindlin (1951) and Vlasov (1957) among others. To enlarge upon this, without wishing to give it a character of exclusiveness and if only for the wide diffusion and length of the work, if we analyze the text of $\mathrm{Zi}$ enkiewicz and Taylor on "Finite Element Method" [9] it can be seen how, starting from what could be considered as the third edition (1980) up to the fourth (CIMME, 1994), the treatment of plate calculation has considerably changed, not only regarding the methodology and didactics of thin plate stresses but also with respect to the connection between thick-thin formulations as well as the inclusion of the numerous recent experiments carried out in thick plates [9]. 
However, the methodology followed to solve the problems of plates differs according to whether a study of thin or thick plates is being made. As is well known, the flexure of thin plates is governed by the biharmonic equation [7]:

$$
\Delta \Delta_{\mathrm{W}}=\frac{\mathrm{p}}{\mathrm{D}}
$$

assuming the hypothesis of Kirchoff . In 1945 Reissner [5] proposed a correction to the previous equation obtained by variational calculation and valid for thick plates, which was:

$$
\mathrm{D} \cdot \Delta \Delta_{\mathrm{W}}=\mathrm{p}-\frac{2-\mu}{10 \cdot(1-\mu)} \mathrm{h}^{2} \cdot \Delta_{\mathrm{p}}
$$

and obviously coincided with the first equation when $\mathrm{h}$ (thickness) was small enough. Parallelly in 1947, Bolle [2] following a totally different theory, it was assumed that the normal to the middle surface of the plate at that point was separated from the displacement $w$ in accordance with the coordinate axes at that point the following two equations were arrived at, also valid for thick plates:

$$
\begin{aligned}
\mathrm{D} \cdot \Delta \Delta_{\mathrm{W}} & =\mathrm{p}-\frac{\Delta_{\mathrm{p}} \cdot 2 \cdot \mathrm{h}^{2}}{10 \cdot(1-\mu)}, \\
\Delta \alpha & =\frac{10}{\mathrm{~h}^{2}} \cdot \alpha,
\end{aligned}
$$

where

$$
\alpha=-\frac{1}{2}\left(\frac{\partial \theta_{x}}{\partial x}+\frac{\partial \theta_{y}}{\partial y}\right),
$$

$\theta_{\mathrm{x}}$ and $\theta_{\mathrm{y}}$ are the normal rotations mentioned previously.

Although, if we follow a chronological order, the names of Mindlin \& Vlasov, among others, should be mentioned, a recent proposal for the calculation of thick plates is owed to Rekach [6]. In this theory, the problem is resolved by means of the following system of differential equations:

$$
\begin{gathered}
\left(\frac{\partial \theta_{\mathrm{x}}}{\partial \mathrm{y}}-\frac{\partial \theta_{\mathrm{y}}}{\partial \mathrm{x}}\right)-\Delta_{\mathrm{W}}=\frac{6}{5} \cdot \frac{\mathrm{p}}{\mathrm{G} \cdot \mathrm{h}}, \\
\Delta \theta_{\mathrm{y}}-\frac{1+\mu}{2} \cdot \frac{\partial}{\partial \mathrm{y}}\left(\frac{\partial \theta_{\mathrm{x}}}{\partial \mathrm{x}}+\frac{\partial \theta_{\mathrm{y}}}{\partial \mathrm{y}}\right)=\frac{5 \cdot(1-\mu)}{\mathrm{h}^{2}} \cdot\left(\theta_{\mathrm{y}}+\frac{\partial_{\mathrm{w}}}{\partial \mathrm{x}}\right) \\
\Delta \theta_{\mathrm{x}}-\frac{1+\mu}{2} \cdot \frac{\partial}{\partial \mathrm{x}}\left(\frac{\partial \theta_{\mathrm{y}}}{\partial \mathrm{y}}+\frac{\partial \theta_{\mathrm{x}}}{\partial \mathrm{x}}\right)=\frac{5 \cdot(1-\mu)}{\mathrm{h}^{2}} \cdot\left(\theta_{\mathrm{x}}+\frac{\partial_{\mathrm{w}}}{\partial \mathrm{y}}\right)
\end{gathered}
$$


and the consequent contour conditions of the plate.

Therefore, in this work we shall demonstrate: 1) our contribution to a more adequate theory; 2) that the second equation of Bolle (4) is unsuitable because that parameter is nil; 3) that the aforementioned system can be expressed more simply and that it can be transformed for its treatment by finite differences since it supplies erroneous; and 4) that the transformed equation system proposed is:

$$
\begin{gathered}
\Delta \Delta_{\mathrm{W}}=\frac{\mathrm{p}}{\mathrm{D}}-\frac{12 \cdot(1+\mu)}{5 \cdot \mathrm{E} \cdot \mathrm{h}} \Delta_{\mathrm{p}_{\mathrm{z}}}, \\
\Delta \theta_{\mathrm{x}}=\frac{5 \cdot(1-\mu)}{\mathrm{h}^{2}} \cdot\left(\theta_{\mathrm{x}}-\frac{\partial_{\mathrm{w}}}{\partial_{\mathrm{y}}}\right), \\
\Delta \theta_{\mathrm{y}}=\frac{5 \cdot(1-\mu)}{\mathrm{h}^{2}} \cdot\left(\theta_{\mathrm{y}}-\frac{\partial_{\mathrm{w}}}{\partial_{\mathrm{x}}}\right)
\end{gathered}
$$

provides the correct solution both in the case of thin and thick plates and also, when the necessary corrections are made to it with the inclusion of nonlinear terms, it permits the study of plates with large flexures (nonlinear calculation).

Finally, we should like to emphasize the usefulness of Von Karman's equation (originally conceived for thin plates) for any type of plate being studied and that it would be valid to transfer the methodology followed to the study of shells this being the subject of a future article.

\section{THE BOLLE - REISSNER PLATE THEORY}

In this theory, which is valid for thick plates, the displacements from one point of the plate are given by:

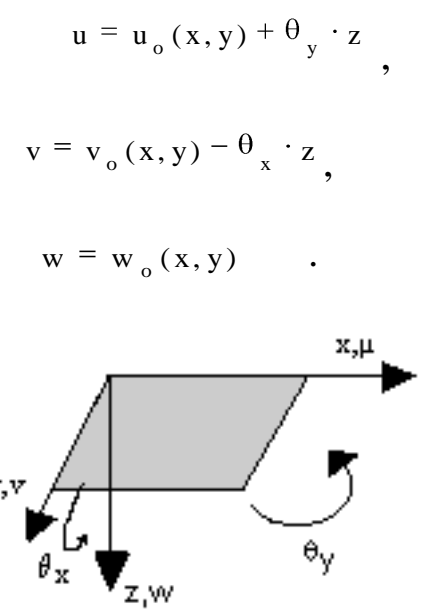

Figure 1.Coodinate System and Sign Criteria.

in which it should be pointed out that although in linear calculation $\mathrm{u}_{\mathrm{O}}$ and $\mathrm{v}_{\mathrm{O}}$ (displacements according to two axes from points on the middle plane of the plate) are nil, we have 
an interest in including them in order to obtain general equations for nonlinear calculation inclusive.

Similarly, according to the current state of opinion, that there is a parabolic distribution, throughout the thickness, of the tangential stresses.

$$
\tau_{\mathrm{xz}}=\alpha \cdot \mathrm{G} \cdot\left(1-\frac{4 \mathrm{z}^{2}}{\mathrm{~h}^{2}}\right) \cdot \gamma_{\mathrm{xz}}
$$

with $\alpha=\frac{5}{4} ;[2],[5]$

$$
\tau_{\mathrm{yz}}=\alpha \cdot \mathrm{G} \cdot\left(1-\frac{4 \mathrm{z}^{2}}{\mathrm{~h}^{2}}\right) \cdot \gamma_{\mathrm{yz}}
$$

The strains are:

$$
\begin{gathered}
\varepsilon_{\mathrm{z}}=0 \\
\varepsilon_{\mathrm{y}}=\varepsilon_{\mathrm{yo}}-\mathrm{z} \cdot \frac{\partial \theta_{\mathrm{x}}}{\partial \mathrm{y}} \\
\varepsilon_{\mathrm{x}}=\frac{\partial_{\mathrm{u}}}{\partial \mathrm{x}}+\frac{1}{2}\left(\frac{\partial_{\mathrm{w}}}{\partial \mathrm{x}}\right)^{2}=\frac{\partial_{\mathrm{u}_{\mathrm{o}}}}{\partial \mathrm{x}}+\mathrm{z} \cdot \frac{\partial \theta_{\mathrm{y}}}{\partial \mathrm{x}}+\frac{1}{2}\left(\frac{\partial_{\mathrm{w}}}{\partial \mathrm{x}}\right)^{2}=\varepsilon_{\mathrm{xo}}+\mathrm{z} \cdot \frac{\partial \theta_{\mathrm{y}}}{\partial \mathrm{x}} \\
\gamma_{\mathrm{xy}}=\frac{\partial_{\mathrm{u}}}{\partial \mathrm{y}}+\frac{\partial_{\mathrm{v}}}{\partial_{\mathrm{x}}}+\frac{\partial_{\mathrm{w}}}{\partial \mathrm{x}} \cdot \frac{\partial_{\mathrm{w}}}{\partial \mathrm{y}}=\gamma_{\mathrm{xyo}}+\mathrm{z} \cdot\left(\frac{\partial \theta_{\mathrm{y}}}{\partial \mathrm{y}}-\frac{\partial \theta_{\mathrm{x}}}{\partial \mathrm{x}}\right) \\
\gamma_{\mathrm{yz}}=\frac{\partial_{\mathrm{v}}}{\partial_{\mathrm{z}}}+\frac{\partial_{\mathrm{w}}}{\theta_{\mathrm{y}}}=-\theta_{\mathrm{x}}+\frac{\partial_{\mathrm{w}}}{\partial_{\mathrm{y}}} \\
\gamma_{\mathrm{xz}}=\frac{\partial_{\mathrm{u}}}{\partial_{\mathrm{z}}}+\frac{\partial_{\mathrm{w}}}{\partial_{\mathrm{x}}}=\theta_{\mathrm{y}}+\frac{\partial_{\mathrm{w}}}{\partial_{\mathrm{x}}}
\end{gathered}
$$

$\varepsilon_{\mathrm{xo}}, \varepsilon_{\mathrm{yo}}, \gamma_{\mathrm{xyo}}$ being the deformations corresponding to the points on the middle plane; the stresses are given by:

$$
\begin{gathered}
\sigma_{x}=\frac{E}{1-\mu^{2}} \cdot\left(\varepsilon_{x}+\mu \varepsilon_{y}\right)=\frac{E}{1-\mu^{2}} \cdot\left[\varepsilon_{x o}+\mu \cdot \varepsilon_{y o}+z \cdot\left(\frac{\partial \theta_{y}}{\theta_{x}}-\mu \cdot \frac{\partial \theta_{x}}{\partial y}\right)\right] \\
\sigma_{y}=\frac{E}{1-\mu^{2}} \cdot\left[\varepsilon_{y o}+\mu \cdot \varepsilon_{x o}+z \cdot\left(-\frac{\partial \theta_{x}}{\partial y}+\mu \cdot \frac{\partial \theta_{y}}{\partial x}\right)\right] \\
\sigma_{z}=\mu \cdot\left(\sigma_{x}+\sigma_{y}\right)
\end{gathered}
$$




$$
\begin{aligned}
& \tau_{x y}=G \cdot\left[\gamma_{x y o}+z \cdot\left(\frac{\partial \theta_{y}}{\partial y}-\frac{\partial \theta_{x}}{\partial x}\right)\right] \\
& \tau_{x z}=\alpha \cdot G \cdot\left(1-\frac{4 z^{2}}{h^{2}}\right) \cdot\left(\theta_{y}+\frac{\partial w}{\partial x}\right) \\
& \tau_{y z}=\alpha \cdot G \cdot\left(1-\frac{4 z^{2}}{h^{2}}\right) \cdot\left(-\theta_{x}+\frac{\partial w}{\partial y}\right)
\end{aligned}
$$

After integrating all along the thickness, we obtain:

$$
\begin{gathered}
\mathrm{N}_{\mathrm{x}}=\frac{\mathrm{E} \cdot \mathrm{h}}{1-\mu^{2}} \cdot\left(\varepsilon_{\mathrm{xo}}+\mu \cdot \varepsilon_{\mathrm{yo}}\right), \\
\mathrm{N}_{\mathrm{y}}=\frac{\mathrm{E} \cdot \mathrm{h}}{1-\mu^{2}} \cdot\left(\varepsilon_{\mathrm{yo}}+\mu \cdot \varepsilon_{\mathrm{xo}}\right), \\
\mathrm{N}_{\mathrm{xy}}=\mathrm{G} \cdot \mathrm{h} \cdot \gamma_{\mathrm{xyo}}, \\
\mathrm{M}_{\mathrm{x}}=\mathrm{D} \cdot\left(\frac{\partial \theta_{\mathrm{y}}}{\partial \mathrm{x}}-\mu \cdot \frac{\partial \theta_{\mathrm{x}}}{\partial \mathrm{y}}\right), \\
\mathrm{M}_{\mathrm{y}}=\mathrm{D} \cdot\left(-\frac{\partial \theta_{\mathrm{x}}}{\partial \mathrm{y}}-\mu \cdot \frac{\partial \theta_{\mathrm{y}}}{\partial \mathrm{x}}\right) ; \\
\mathrm{M}_{\mathrm{xy}}=\frac{\mathrm{h}^{3} \cdot \mathrm{G}}{12} \cdot\left(\frac{\partial \theta_{\mathrm{y}}}{\partial \mathrm{y}}-\frac{\partial \theta_{\mathrm{x}}}{\partial \mathrm{x}}\right) \\
\mathrm{N}_{\mathrm{xz}}=\frac{5}{6} \cdot \mathrm{h} \cdot \mathrm{G} \cdot\left(\theta_{\mathrm{y}}+\frac{\partial_{\mathrm{w}}}{\partial \mathrm{x}}\right)
\end{gathered}
$$

and

$$
\mathrm{N}_{\mathrm{yz}}=\frac{5}{6} \cdot \mathrm{h} \cdot \mathrm{G} \cdot\left(\frac{\partial_{\mathrm{w}}}{\partial_{\mathrm{y}}}-\theta_{\mathrm{x}}\right) .
$$




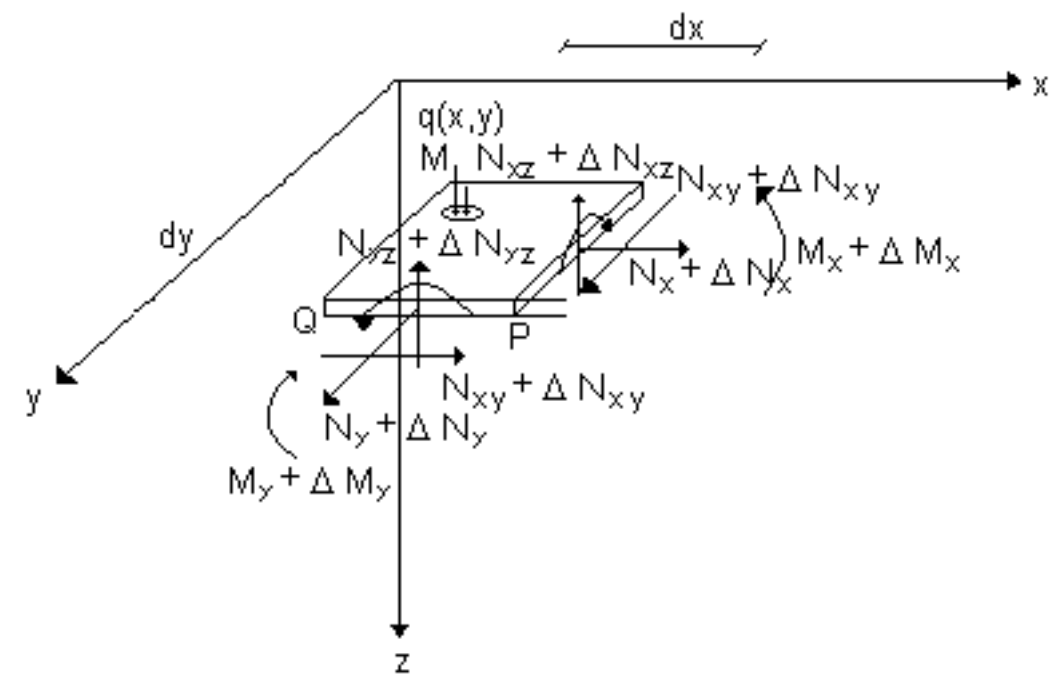

Figure 2: Plate element. Thin plates

\section{EQUATIONS OF EQUILIBRIUM OF THE PLATE ELEMENT IN ITS DEFOR- MED CONFIGURATION}

Although, traditionally, the establishment of equilibrium equations has been realized in the initial non-deformed configuration, we, however, needed to establish it in deformed geometry (bent plate) in order to obtain the relation which permitted us to simplify and generalize he Bolle equations, which is none than a way to proceed following the methodology used in [6].



Figure 3.Plate element in deformed configuration

$$
\frac{\partial \mathrm{t}_{\mathrm{x}}}{\partial_{\mathrm{x}}}=-\frac{\partial \theta_{\mathrm{y}}}{\partial \mathrm{x}} \cdot \overrightarrow{\mathrm{k}},
$$




$$
\begin{aligned}
& \frac{\partial t_{y}}{\partial x}=\frac{\partial \theta_{x}}{\partial x} \cdot \vec{k}, \\
& \frac{\partial \mathrm{t}_{\mathrm{x}}}{\partial \mathrm{y}}=-\frac{\partial \theta_{\mathrm{y}}}{\partial \mathrm{y}} \cdot \overrightarrow{\mathrm{k}},
\end{aligned}
$$

and

$$
\frac{\partial \mathrm{t}_{\mathrm{y}}}{\partial \mathrm{y}}=-\frac{\partial \theta_{\mathrm{x}}}{\partial \mathrm{y}} \cdot \overrightarrow{\mathrm{k}}
$$

Let Figures (2) and (3) represent a plate element, on one hand subjected to stresses in which we have omitted the operators on the sides not seen for a greater clarity of the figure (2), and on the other, the real geometric configuration in which is produced the equilibrium corresponding to that which the element adopts once the plate is bent.

To obtain the necessary equations, it was only necessary to consider the equations of Statics in the element:

$$
\begin{aligned}
& \sum_{\mathrm{F}_{\mathrm{ext}}}^{\rightarrow}+\sum_{\mathrm{F}_{\mathrm{QM}}}^{\rightarrow}+\sum_{\mathrm{F}_{\mathrm{MN}}}+\Sigma_{\mathrm{F}_{\mathrm{PN}}}+\Sigma_{\mathrm{F}_{\mathrm{PQ}}}=\overrightarrow{0} \\
& \sum \vec{M}=\overrightarrow{0}=\sum \vec{M}_{Q M}+\sum \vec{M}_{M N}+\sum \vec{M}_{P N}+\sum \vec{M}_{P Q}-N_{x z} \cdot d x \cdot d y \vec{t}_{y}+N_{y z} \cdot d x \cdot d y t_{x}+N_{x y} \cdot d x \cdot d y \cdot \vec{k}-N_{x y} \cdot d x \cdot d y \cdot \vec{k} \\
& \sum \underset{F_{Q M}}{\rightarrow}=\left(-N_{x} \cdot t_{x}-N_{x y} \cdot \overrightarrow{t_{y}}-N_{x z} \cdot \vec{k}\right) \cdot d s_{1} \\
& \sum F_{M N}=\left(-N_{y} \cdot t_{y}-N_{x y} \cdot t_{x}-N_{y z} \cdot \vec{k}\right) \cdot d s_{2} \\
& \sum_{F_{P M}}^{\rightarrow}=\left[N_{x} \cdot \overrightarrow{t_{x}}+d\left(N_{x} \cdot t_{x}\right)+N_{x y} \cdot t_{y}+d\left(N_{x y} \cdot t_{y}\right)+N_{x z} \cdot \vec{k}+d\left(N_{x z} \cdot \vec{k}\right)\right] \cdot d s_{1}
\end{aligned}
$$

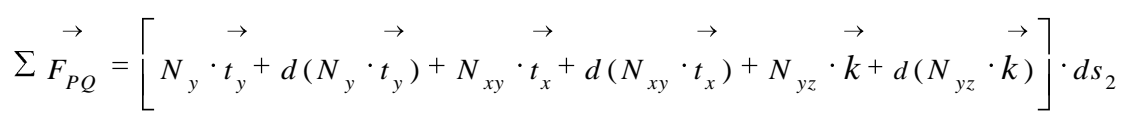

bearing in mind that we go from the QM edge to the PN varying according to the axis $\mathrm{x}$ (with $\mathrm{y}=\mathrm{cte})$ so that, for example:

$$
d\left(N_{x} \cdot \vec{t}_{x}\right)=\frac{\partial N_{x}}{\partial x} \cdot d x \cdot t_{x}+\frac{\partial \vec{t}_{x}}{\partial x} \cdot d x \cdot N_{x}
$$

and from the MN edge to the QP with $\mathrm{x}=$ cte, so that, for example: 


$$
d\left(N_{x y} \cdot \vec{t}_{x}\right)=\frac{\partial N_{x y}}{\partial y} \cdot d y \cdot \vec{t}_{x}+N_{x y} \cdot \frac{\partial \vec{t}_{x}}{\partial y} \cdot d y
$$

that

$$
\mathrm{ds}_{1} \approx \mathrm{dx}, \mathrm{ds}_{2} \approx \mathrm{dy}
$$

and the values of those derived from the unit vector quantities $\overrightarrow{t_{x}}, \overrightarrow{t_{y}}$, we find that the vector equation

$$
\Sigma_{\mathrm{F}}=\overrightarrow{0}
$$

gives us

$$
\begin{gathered}
\frac{\partial \mathbf{N}_{\mathbf{x}}}{\partial \mathbf{x}}+\frac{\partial \mathbf{N}_{\mathrm{xy}}}{\partial \mathbf{y}}=0 \\
\frac{\partial \mathbf{N}_{\mathrm{xy}}}{\partial \mathrm{x}}+\frac{\partial \mathbf{N}_{\mathrm{y}}}{\partial \mathrm{y}}=0 \\
\frac{\partial \mathbf{N}_{\mathrm{xz}}}{\partial \mathrm{x}}+\frac{\partial \mathbf{N}_{\mathrm{yz}}}{\partial \mathbf{y}}+\mathrm{q}-\mathbf{N}_{\mathrm{x}} \cdot \frac{\partial \theta_{\mathrm{y}}}{\partial \mathbf{x}}+\mathbf{N}_{\mathrm{y}} \cdot \frac{\partial \theta_{\mathrm{x}}}{\partial \mathrm{y}}+\mathbf{N}_{\mathrm{xy}} \cdot\left(\frac{\partial \theta_{\mathrm{x}}}{\partial \mathbf{x}}-\frac{\partial \theta_{\mathrm{y}}}{\partial \mathbf{y}}\right)=0
\end{gathered}
$$

Proceeding in the same manner, the vector equation

$$
\Sigma_{\mathrm{M}}=\overrightarrow{0}
$$

gives us:

$$
\begin{gathered}
\frac{\partial \mathbf{M}_{\mathbf{x}}}{\partial \mathbf{x}}+\frac{\partial \mathbf{M}_{\mathrm{xy}}}{\partial \mathbf{y}}-\mathbf{N}_{\mathrm{xz}}=0 \\
\frac{\partial \mathbf{M}_{\mathrm{xy}}}{\partial \mathbf{x}}+\frac{\partial \mathbf{M}_{\mathbf{y}}}{\partial \mathbf{y}}-\mathbf{N}_{\mathrm{yz}}=0 \\
\mathbf{M}_{\mathbf{x}} \cdot \frac{\partial \theta_{\mathbf{x}}}{\partial \mathbf{x}}+\mathbf{M}_{\mathrm{y}} \cdot \frac{\partial \theta_{\mathrm{y}}}{\partial \mathbf{y}}+\mathbf{M}_{\mathrm{xy}} \cdot\left(\frac{\partial \theta_{\mathrm{y}}}{\partial \mathbf{x}}+\frac{\partial \theta_{\mathbf{x}}}{\partial \mathbf{y}}\right)=0
\end{gathered}
$$

Now if, in the sixth equation, we substitute $M_{X}, M_{y}$ and $M_{x y}$ for their values shown in the previous section, we find it can be transformed in

$$
\frac{\mathrm{D} \cdot(1+\mu)}{2} \cdot\left(\frac{\partial \theta_{\mathrm{y}}}{\partial \mathrm{y}}+\frac{\partial \theta_{\mathrm{x}}}{\partial \mathrm{x}}\right) \cdot\left(\frac{\partial \theta_{\mathrm{y}}}{\partial \mathrm{x}}-\frac{\partial \theta_{\mathrm{x}}}{\partial \mathrm{y}}\right)=0
$$

but if we note that: 


$$
\frac{\partial \theta_{y}}{\partial x}-\frac{\partial \theta_{x}}{\partial y}=\frac{1}{D \cdot(1+\mu)} \cdot\left(M_{x}+M_{y}\right)
$$

cannot be zero for all the points on the plate, we reach the conclusion that:

$$
\frac{\partial \theta_{y}}{\partial y}+\frac{\partial \theta_{x}}{\partial x}=0 \longrightarrow \frac{\partial \theta_{y}}{\partial y}=-\frac{\partial \theta_{x}}{\partial x}
$$

which demonstrates the unsuitability of Bole's second equation mentioned in the first paragraph.

By substituting the bending moments, twisting moments and shearing forces values in the first five equations and omitting the subindex indicative that the displacements corresponding to the points on the middle plane, we find the following differential equation system which could be denominated as "more general than that of Bolle - Reissner" and of which that already commented is a special case in point 1 (in Reference [6] only for linear calculation):

$$
\begin{gathered}
\mathrm{u}_{\mathrm{x}^{2}}^{\prime \prime}+\frac{1+\mu}{2} \cdot \mathrm{v}_{\mathrm{xy}}^{\prime \prime}+\frac{1-\mu}{2} \cdot \mathrm{u}_{\mathrm{y}^{2}}^{\prime \prime}=-\left(\mathrm{w}_{\mathrm{x}}^{\prime} \cdot \mathrm{w}_{\mathrm{x}^{2}}{ }^{2}+\mu \cdot \mathrm{w}_{\mathrm{y}}^{\prime} \cdot \mathrm{w}_{\mathrm{xy}}^{\prime \prime}\right)-\frac{1-\mu}{2} \cdot\left(\mathrm{w}_{\mathrm{y}}^{\prime} \cdot \mathrm{w}_{\mathrm{xy}}^{\prime \prime}+\mu \cdot \mathrm{w}_{\mathrm{x}}^{\prime} \cdot \mathrm{w}_{\mathrm{y}}{ }^{2}\right) \\
\frac{1-\mu}{2} \cdot \mathrm{v}_{\mathrm{x}^{2}}^{\prime \prime}+\frac{1+\mu}{2} \cdot \mathrm{u}_{\mathrm{xy}}^{\prime \prime}+\mathrm{v}_{\mathrm{y}^{2}}^{\prime \prime}=-\left(\mathrm{w}_{\mathrm{y}}^{\prime} \cdot \mathrm{w}_{\mathrm{y}^{2}}{ }^{2}+\mu \cdot \mathrm{w}_{\mathrm{x}}^{\prime} \cdot \mathrm{w}_{\mathrm{xy}}^{\prime \prime}\right)-\frac{1-\mu}{2} \cdot\left(\mathrm{w}_{\mathrm{y}}^{\prime} \cdot \mathrm{w}_{\mathrm{x}^{2}}^{\prime \prime}+\mu \cdot \mathrm{w}_{\mathrm{x}}^{\prime} \cdot \mathrm{w}_{\mathrm{xy}}^{\prime \prime}\right) \\
\Delta_{\mathrm{w}}-\frac{\partial \theta_{\mathrm{x}}}{\partial \mathrm{y}}+\frac{\partial \theta_{\mathrm{y}}}{\partial \mathrm{x}}=\frac{12 \cdot(1+\mu)}{5 \cdot \mathrm{E} \cdot \mathrm{h}} \cdot\left[-\mathrm{q}+\mathrm{N}_{\mathrm{x}} \cdot \frac{\partial \theta_{\mathrm{y}}}{\partial \mathrm{x}}-\mathrm{N}_{\mathrm{y}} \cdot \frac{\partial \theta_{\mathrm{x}}}{\partial \mathrm{y}}+\mathrm{N}_{\mathrm{xy}} \cdot\left(\frac{\partial \theta_{\mathrm{x}}}{\partial \mathrm{x}}-\frac{\partial \theta_{\mathrm{y}}}{\partial \mathrm{y}}\right)\right] \\
\Delta \theta_{\mathrm{y}}-\frac{1+\mu}{2} \cdot \frac{\partial}{\partial \mathrm{y}}\left(\frac{\partial \theta_{\mathrm{x}}}{\partial \mathrm{x}}+\frac{\partial \theta_{\mathrm{y}}}{\partial \mathrm{y}}\right)=\frac{5 \cdot(1-\mu)}{\mathrm{h}^{2}} \cdot\left(\theta_{\mathrm{y}}+\frac{\partial_{\mathrm{w}}}{\partial \mathrm{x}}\right) \\
\Delta \theta_{\mathrm{x}}-\frac{1+\mu}{2} \cdot \frac{\partial}{\partial \mathrm{x}}\left(\frac{\partial \theta_{\mathrm{x}}}{\partial \mathrm{x}}+\frac{\partial \theta_{\mathrm{y}}}{\partial \mathrm{y}}\right)=\frac{5 \cdot(1-\mu)}{\mathrm{h}^{2}} \cdot\left(\theta_{\mathrm{x}}-\frac{\partial_{\mathrm{w}}}{\partial \mathrm{y}}\right)
\end{gathered}
$$

which does not take into account the important condition, given by (60), which is fundamental in thin plates. Indeed, in them, as

$$
\theta_{\mathrm{y}}=-\frac{\partial_{\mathrm{w}}}{\partial_{\mathrm{x}}}, \theta_{\mathrm{x}}=\frac{\partial_{\mathrm{w}}}{\partial_{\mathrm{y}}}
$$

the condition (60) shows us:

$$
\frac{\partial^{2} w}{\partial x \partial y}=\frac{\partial^{2} w}{\partial y \partial_{x}}
$$

In short, after incorporating this condition, we are left with a first simplified system which, by recognizing the reality of the deformation conceptually moves away from the initial Bolle hypothesis: 


$$
\begin{aligned}
& \mathrm{u}_{\mathrm{x}^{2}}^{\prime \prime}+\frac{1+\mu}{2} \cdot \mathrm{v}_{\mathrm{xy}}^{\prime \prime}+\frac{1-\mu}{2} \cdot \mathrm{u}_{\mathrm{y}^{2}}^{\prime \prime}=-\left(\mathrm{w}_{\mathrm{x}}^{\prime} \cdot \mathrm{w}_{\mathrm{x}^{2}}^{\prime \prime}+\mu \cdot \mathrm{w}_{\mathrm{y}}^{\prime} \cdot \mathrm{w}_{\mathrm{xy}}^{\prime \prime}\right)-\frac{1-\mu}{2} \cdot\left(\mathrm{w}_{\mathrm{y}}^{\prime} \cdot \mathrm{w}_{\mathrm{xy}}^{\prime \prime}+\mathrm{w}_{\mathrm{x}}^{\prime} \cdot \mathrm{w}_{\mathrm{y}^{2}}^{\prime \prime}\right), \\
& \frac{1-\mu}{2} \cdot v_{x^{2}}^{\prime \prime}+\frac{1+\mu}{2} u_{x y}^{\prime \prime}+v_{y^{2}}^{\prime \prime}=-\left(w_{y}^{\prime} \cdot w_{y^{2}}^{\prime \prime}+\mu \cdot w_{x}^{\prime} \cdot w_{x y}^{\prime \prime}\right)-\frac{1-\mu}{2} \cdot\left(w_{y}^{\prime} w_{x^{2}}^{\prime \prime}+w_{x}^{\prime} w_{x y}^{\prime \prime}\right), \\
& \Delta_{\mathrm{W}}-\frac{\partial \theta_{\mathrm{x}}}{\partial \mathrm{y}}+\frac{\partial \theta_{\mathrm{y}}}{\partial \mathrm{x}}=\frac{12 \cdot(1+\mu)}{5 \cdot \mathrm{E} \cdot \mathrm{h}} \cdot\left[-\mathrm{q}+\mathrm{N}_{\mathrm{x}} \cdot \frac{\partial \theta_{\mathrm{y}}}{\partial \mathrm{x}}-\mathrm{N}_{\mathrm{y}} \cdot \frac{\partial \theta_{\mathrm{x}}}{\partial \mathrm{y}}+\mathrm{N}_{\mathrm{xy}} \cdot\left(\frac{\partial \theta_{\mathrm{x}}}{\partial \mathrm{x}}-\frac{\partial \theta_{\mathrm{y}}}{\partial \mathrm{y}}\right)\right], \\
& \Delta \theta_{\mathrm{y}}=\frac{5 \cdot(1-\mu)}{\mathrm{h}^{2}} \cdot\left(\theta_{\mathrm{y}}+\frac{\partial_{\mathrm{w}}}{\partial \mathrm{x}}\right) \\
& \Delta \theta_{\mathrm{x}}=\frac{5 \cdot(1-\mu)}{\mathrm{h}^{2}} \cdot\left(\theta_{\mathrm{x}}-\frac{\partial_{\mathrm{w}}}{\partial \mathrm{y}}\right)
\end{aligned}
$$

\section{RESOLUTION AND CONTRASTING OF RESULTS OBTAINED IN LINEAR CALCULATION BY THE FINITE DIFFERENCE METHOD}

In the supposition of proceeding to a linear analysis, the first two equations are automatically satisfied with

$$
\mathrm{u}=\mathrm{v}=0
$$

and the other three leave us with:

$$
\begin{gathered}
\Delta_{\mathrm{W}}-\frac{\partial \theta_{\mathrm{x}}}{\partial \mathrm{y}}+\frac{\partial \theta_{\mathrm{y}}}{\partial \mathrm{x}}=-\frac{12 \cdot(1+\mu) \cdot \mathrm{q}}{5 \cdot \mathrm{E} \cdot \mathrm{h}}, \\
\Delta \theta_{\mathrm{y}}=\frac{5 \cdot(1-\mu)}{\mathrm{h}^{2}} \cdot\left(\theta_{\mathrm{y}}+\frac{\partial_{\mathrm{w}}}{\partial \mathrm{x}}\right), \\
\Delta \theta_{\mathrm{x}}=\frac{5 \cdot(1-\mu)}{\mathrm{h}^{2}} \cdot\left(\theta_{\mathrm{x}}-\frac{\partial_{\mathrm{w}}}{\partial_{\mathrm{y}}}\right),
\end{gathered}
$$

As only first and second derivatives intervene, it was clear that this greatly facilitated their programming by the finite differences method. However, and in spite of having incorporated this important condition (60), it was immediately perceived that phenomena of numeric instability appeared for thin plates in which the thick plates are less or equal to a tenth of the side $(1 / 10)$, with the obtaining of results totally removed from reality, whilst for thick plates these phenomena disappeared and completely satisfactory results were obtained.

As a reference, we took a square plate $4 \mathrm{x} 4 \mathrm{~m}, \mu=0,30, \mathrm{E}=2 \cdot 10^{6} \mathrm{t} \pi / \mathrm{m}^{2}$ both built-in and supported on its four sides, and for checking results, those provided by the Ansys programme of E.F. in which we adopted as an element the 8-node parallelepiped with four elements in the thickness and subdivision of 16x16 inplane in order to obtain the behavi- 
our of the plate as a tridimensional solid. Therefore, for the built-in plate, with thicknesses comprised between

$$
\frac{1}{10} \leq \mathrm{e} \leq \frac{1}{4} \text { (thick plate) }
$$

the error in the maximum flexure varied between $10 \%$ and $1,1 \%$, whilst with the thin plate theory errors of between $9 \%$ and $51 \%$ were found. Conversely, for thicknesses of

$$
\frac{1}{80} \leq \mathrm{e} \leq \frac{1}{10} \quad(\text { thin plate })
$$

the thin plate theory error varied from 3 to $9 \%$ whereas with the previous equations and D.F. the variation range was between 80 and $10 \%$. Analogous results would be observed in the case of supported plates and of various situations of loading.

From then on we were faced with two possibilities: either we had to look for a contrivance in order, by taking these equations, to obtain correct solutions for thin plates or we had to transform the equations with the same objective in mind. When we followed the first option we found that, after the first step, we did resolve the system

$$
\begin{aligned}
& \Delta \theta_{\mathrm{x}}=0 \\
& \Delta \theta_{\mathrm{y}}=0 \\
& \Delta_{\mathrm{W}}-\frac{\partial \theta_{\mathrm{x}}}{\partial \mathrm{y}}+\frac{\partial \theta_{\mathrm{y}}}{\partial \mathrm{x}}=-\frac{12 \cdot(1+\mu) \cdot \mathrm{q}}{5 \cdot \mathrm{E} \cdot \mathrm{h}}
\end{aligned}
$$

and with the solution obtained for $\theta_{\mathbf{x}}, \theta_{\mathrm{y}}, \mathrm{w}$;

$$
\frac{\partial_{\mathrm{w}}}{\partial_{\mathrm{x}}}, \frac{\partial_{\mathrm{w}}}{\partial_{\mathrm{y}}}
$$

we solve

$$
\begin{gathered}
\Delta \theta_{\mathrm{x}}=\frac{5 \cdot(1-\mu)}{\mathrm{h}^{2}} \cdot\left(\theta_{\mathrm{x}}-\frac{\partial_{\mathrm{W}}}{\partial_{\mathrm{y}}}\right), \\
\Delta \theta_{\mathrm{y}}=\frac{5 \cdot(1-\mu)}{\mathrm{h}^{2}} \cdot\left(\theta_{\mathrm{y}}+\frac{\partial_{\mathrm{w}}}{\partial \mathrm{x}}\right), \\
\Delta \mathrm{W}-\frac{\partial \theta_{\mathrm{x}}}{\partial \mathrm{y}}+\frac{\partial \theta_{\mathrm{y}}}{\partial \mathrm{x}}=-\frac{12 \cdot(1+\mu) \cdot \mathrm{q}}{5 \cdot \mathrm{E} \cdot \mathrm{h}} .
\end{gathered}
$$

entering as known values the previous ones in the second members of the equations, we obtained correct values for the solution for all the loading states and thicknesses, thick and thin, which we have proven. However, this contrivance which at first seemed to us to be a hopeful 
solution, had to be rejected for its inefficacy in studies which took into consideration a geometric non linearity.

\section{GENERAL TRANSFORMED EQUATIONS}

Following the path posited by Bolle [2], from the third equation we obtained:

$$
\Delta \Delta_{\mathrm{W}}+\frac{\partial}{\partial \mathrm{x}} \Delta \theta_{\mathrm{y}}-\frac{\partial}{\partial \mathrm{y}} \Delta \theta_{\mathrm{x}}=-12 \cdot \frac{(1+\mu)}{5 \cdot \mathrm{E} \cdot \mathrm{h}} \cdot \Delta_{\mathrm{q}}
$$

whilst from the 1st and 2nd we found

$$
\begin{aligned}
& \frac{\partial}{\partial x} \Delta \theta_{y}-\frac{\partial}{\partial y} \Delta \theta_{x}=\frac{5 \cdot(1-\mu)}{h^{2}} \cdot\left(\frac{\partial \theta_{y}}{\partial x}+\frac{\partial^{2} w}{\partial_{x}{ }^{2}}-\frac{\partial \theta_{x}}{\partial y}+\frac{\partial^{2} w}{\partial_{y}{ }^{2}}\right)= \\
& =\frac{5 \cdot(1-\mu)}{h^{2}} \cdot \frac{12 \cdot(1+\mu)}{5 \cdot E \cdot h} \cdot\left[-q^{2}+N_{x} \cdot \frac{\partial \theta_{y}}{\partial x}-N_{y} \cdot \frac{\partial \theta_{x}}{\partial y}+2 \cdot N_{x y} \cdot \frac{\partial \theta_{x}}{\partial x}\right]
\end{aligned}
$$

and substituting in the previous equation

$$
\Delta \Delta_{\mathrm{W}}=\frac{\mathrm{q}}{\mathrm{D}}-\frac{12 \cdot(1+\mu)}{5 \cdot \mathrm{E} \cdot \mathrm{h}} \cdot \Delta_{\mathrm{q}}
$$

so that the equation system for the linear case resulted as:

$$
\begin{gathered}
\Delta \theta_{\mathrm{x}}-\frac{5 \cdot(1-\mu)}{\mathrm{h}^{2}} \cdot\left(\theta_{\mathrm{x}}-\frac{\partial_{\mathrm{w}}}{\partial_{\mathrm{y}}}\right)=0 \\
\Delta \theta_{\mathrm{y}}-\frac{5 \cdot(1-\mu)}{\mathrm{h}^{2}} \cdot\left(\theta_{\mathrm{y}}+\frac{\partial_{\mathrm{W}}}{\partial_{\mathrm{x}}}\right)=0 \\
\Delta \Delta_{\mathrm{W}}=\frac{\mathrm{q}}{\mathrm{D}}-\frac{12 \cdot(1+\mu)}{5 \cdot \mathrm{E} \cdot \mathrm{h}} \cdot \Delta_{\mathrm{q}}
\end{gathered}
$$

which constitutes a system of differential equations of general characteristics for the linear study of plates.

For a case of geometric nonlinearity (large flexures), the expanded system to be considered is

$$
\begin{gathered}
u_{x^{2}}^{\prime \prime}+\frac{1+\mu}{2} \cdot v_{x y}^{\prime \prime}+\frac{1-\mu}{2} \cdot u_{y^{2}}^{\prime \prime}=-\left(w_{x}^{\prime} \cdot w_{x^{2}}^{\prime \prime}+\mu \cdot w_{y}^{\prime} \cdot w_{x y}^{\prime \prime}\right)-\frac{1-\mu}{2} \cdot\left(w_{y}^{\prime} \cdot w_{x y}^{\prime \prime}+w_{x}^{\prime} \cdot w_{y^{2}}^{\prime \prime}\right) \\
\frac{1-\mu}{2} \cdot v_{x^{2}}^{\prime \prime}+\frac{1+\mu}{2} \cdot u_{x y}^{\prime \prime}+v_{y^{2}}^{\prime \prime}=-\left(w_{y}^{\prime} \cdot w_{y^{2}}^{\prime \prime}+\mu \cdot w_{x}^{\prime} \cdot w_{x y}^{\prime \prime}\right)-\frac{1-\mu}{2} \cdot\left(w_{y}^{\prime} \cdot w_{x^{2}}^{\prime \prime}+w_{x}^{\prime} \cdot w_{x y}^{\prime \prime}\right) \\
\Delta \theta_{y}-\frac{5 \cdot(1-\mu)}{h^{2}} \cdot\left(\theta_{y}+\frac{\partial w}{\partial x}\right)=0
\end{gathered}
$$




$$
\begin{gathered}
\Delta \theta_{\mathrm{x}}-\frac{5 \cdot(1-\mu)}{\mathrm{h}^{2}} \cdot\left(\theta_{\mathrm{x}}-\frac{\partial_{\mathrm{W}}}{\partial \mathrm{y}}\right)=0 \\
\Delta \Delta_{\mathrm{W}}=-\frac{1}{\mathrm{D}} \cdot\left[-\mathrm{q}+\mathrm{N}_{\mathrm{x}} \cdot \frac{\partial \theta_{\mathrm{y}}}{\partial \mathrm{x}}-\mathrm{N}_{\mathrm{y}} \cdot \frac{\partial \theta_{\mathrm{x}}}{\partial_{\mathrm{y}}}+2 \cdot \mathrm{N}_{\mathrm{xy}} \cdot \frac{\partial \theta_{\mathrm{x}}}{\partial \mathrm{x}}\right]-\frac{12 \cdot(1+\mu)}{5 \cdot \mathrm{E} \cdot \mathrm{h}} \cdot \Delta_{\mathrm{q}}
\end{gathered}
$$

\section{ANALYTICAL RESOLUTION OF THE LINEAR CASE}

In view of the structure of the system $(91,92,93)$ in which the biharmonic equation of thin plates is included, it is easily deduced that the whole range of solutions developed for the study of thin plates is easily transferable for its use in the present context and therefore for obtaining general valid solutions independently of the plate thickness values. We shall now obtain solutions for the case of supported and fitted rectangular plates.

Indeed, consider a simply supported rectangular plate with a sinusoidal loading

$$
\mathrm{q}=\mathrm{q}_{\mathrm{o}} \cdot \operatorname{sen} \frac{\pi_{\mathrm{x}}}{\mathrm{a}} \cdot \operatorname{sen} \frac{\pi_{\mathrm{y}}}{\mathrm{b}} \text { [7] }
$$

Figure 4. Plate Dimensions

It is confirmed that all the boundary conditions are fulfilled if the displacements $\mathrm{w}$ are expressed by

$$
w=c \cdot \operatorname{sen} \frac{\pi_{x}}{a} \cdot \operatorname{sen} \frac{\pi_{y}}{b}
$$

After deriving and substituting in (93) we find

$$
\mathrm{c}=\frac{\mathrm{q}_{\mathrm{o}}}{\mathrm{D} \cdot \pi^{4} \cdot\left(\frac{1}{\mathrm{a}^{2}}+\frac{1}{\mathrm{~b}^{2}}\right)} \cdot\left[\frac{1}{\left(1 / \mathrm{a}^{2}+1 / \mathrm{b}^{2}\right)}+\frac{\mathrm{h}^{2}}{5 \cdot(1-\mu)}\right]
$$

where the second summing is of little relative importance compared to the first when it is a thin plate. Hence, it constitutes a correction to the solution obtained for this type of plate and it is clear that it acquires some relevance as thickness $\mathrm{h}$ increases. In the same way, if for $\theta_{\mathbf{X}}$ and $\theta_{\mathrm{y}}$ we adopt

$$
\theta_{x}=c_{1} \cdot \operatorname{sen} \frac{\pi_{x}}{a} \cdot \cos \frac{\pi_{y}}{b}
$$




$$
\theta_{\mathrm{y}}=\mathrm{c}_{2} \cdot \cos \frac{\pi_{\mathrm{x}}}{\mathrm{a}} \cdot \operatorname{sen} \frac{\pi_{\mathrm{y}}}{\mathrm{b}}
$$

and substitute in (91) and (92)

$$
\begin{aligned}
& \Delta \theta_{x}-\frac{5 \cdot(1-\mu)}{h^{2}} \cdot\left(\theta_{x}-\frac{\partial_{\mathrm{w}}}{\partial_{\mathrm{y}}}\right)=0 \\
& \Delta \theta_{\mathrm{y}}-\frac{5 \cdot(1-\mu)}{\mathrm{h}^{2}} \cdot\left(\theta_{\mathrm{y}}+\frac{\partial_{\mathrm{w}}}{\partial_{\mathrm{x}}}\right)=0
\end{aligned}
$$

we determine $\mathrm{c}_{1}$ and $\mathrm{c}_{2}$ and thus, after substitution in the general expressions, we obtain

$$
\begin{aligned}
& M_{x}=D \cdot\left(-c_{2} \cdot \frac{\pi}{a}+\mu \cdot c_{1} \cdot \frac{\pi}{b}\right) \cdot \operatorname{sen} \frac{\pi_{x}}{a} \cdot \operatorname{sen} \frac{\pi_{y}}{b}, \\
& M_{y}=D \cdot\left(-c_{1} \cdot \frac{\pi}{b}-\mu \cdot c_{2} \cdot \frac{\pi}{a}\right) \cdot \operatorname{sen} \frac{\pi_{x}}{a} \cdot \operatorname{sen} \frac{\pi y}{b} .
\end{aligned}
$$

which are merely corrections of the expressions found in the literature which have been derived for the particular case of thin plates. If the sinusoidal load is given by

$$
\mathrm{q}=\mathrm{q}_{\mathrm{o}} \cdot \operatorname{sen} \frac{\mathrm{m} \pi_{\mathrm{x}}}{\mathrm{a}} \cdot \operatorname{sen} \frac{\mathrm{n} \pi_{\mathrm{y}}}{\mathrm{b}}
$$

where $\mathrm{m}$ and $\mathrm{n}$ are integral numbers, we proceed as before and for the constant $\mathrm{c}$ we obtain

$$
\mathrm{c}=\frac{\mathrm{q}_{\mathrm{o}}}{\mathrm{D} \cdot \pi^{4} \cdot\left(\frac{\mathrm{m}}{\mathrm{a}^{2}}+\frac{\mathrm{n}}{\mathrm{b}^{2}}\right)} \cdot\left[\frac{1}{\left(\mathrm{~m}^{2} / \mathrm{a}^{2}+\mathrm{n}^{2} / \mathrm{b}^{2}\right)}+\frac{\mathrm{h}^{2}}{5 \cdot(1-\mu)}\right]
$$

The case of any loads, for plates with these support conditions, is approached following the methodology in the reference literature, merely assuming the load to be in the following form

$$
\mathrm{q}=\sum \sum_{\mathrm{a}_{\mathrm{mn}}} \cdot \operatorname{sen} \frac{\mathrm{m} \pi_{\mathrm{x}}}{\mathrm{a}} \cdot \operatorname{sen} \frac{\mathrm{n} \pi_{\mathrm{y}}}{\mathrm{b}}
$$

in which case the solution for each of the terms is that which we have just explained. For the particular case of the uniform load, the solution is given by

$$
\mathrm{w}=\frac{16 \cdot \mathrm{q}_{\mathrm{o}}}{\pi^{6} \cdot \mathrm{D}} \cdot \sum_{\mathrm{m}=1,3 \ldots \mathrm{m}=1,3 \ldots}^{\infty} \frac{1}{\mathrm{mn}} \cdot \frac{1}{\left(\frac{\mathrm{m}}{\mathrm{a}}\right)^{2} \cdot\left(\frac{\mathrm{n}}{\mathrm{b}}\right)^{2}} \cdot\left\{\frac{1}{\left(\frac{\mathrm{m}}{\mathrm{a}}\right)^{2}+\left(\frac{\mathrm{n}}{\mathrm{b}}\right)^{2}}+\frac{\mathrm{h}^{2}}{5 \cdot(1-\mu)}\right\} \cdot \operatorname{sen} \frac{\mathrm{m} \pi_{\mathrm{x}}}{\mathrm{a}} \cdot \operatorname{sen} \frac{\mathrm{n} \pi_{\mathrm{y}}}{\mathrm{b}}
$$

It is therefore clear that the resolution, by means of these general equations, of other cases of plates and boundary and load conditions, is simply an exercise in revising known methodologies, expressions and ways of proceeding which thus lead us to general valid expressions for every thickness. 


\section{FINAL OBSERVATION}

Following the reasoning in the previous point, and since the biharmonic equation of thin plates is included in the general system $(91,92,93)$, it would seem logical to assume that the numerical instability problems have been solved. Indeed, we can affirm with satisfaction that for all the cases tested, with different types of dimensions, thicknesses and loading and contour conditions, the solutions found have been completely satisfactory, including the determination of buckling loads in plates and geometric nonlinearity studies (large flexures). The solution to which we refer as an example is that which appears in Graph 1 indicated by sings.

With regard to geometric nonlinearity studies more can be said. Taking into account that

$$
\begin{gathered}
\mathrm{N}_{\mathrm{x}}=\frac{\mathrm{E} \cdot \mathrm{h}}{1-\mu^{2}} \cdot\left[\frac{\partial_{\mathrm{u}}}{\partial \mathrm{x}}+\frac{1}{2}\left(\mathrm{w}_{\mathrm{x}}^{\prime}\right)^{2}+\mu \cdot \frac{\partial_{\mathrm{v}}}{\partial \mathrm{y}}+\frac{1}{2}\left(\mathrm{w}_{\mathrm{y}}^{\prime}\right)^{2}\right], \\
\mathrm{N}_{\mathrm{y}}=\frac{\mathrm{E} \cdot \mathrm{h}}{1-\mu^{2}} \cdot\left[\frac{\partial_{\mathrm{v}}}{\partial \mathrm{y}}+\frac{1}{2}\left(\mathrm{w}_{\mathrm{y}}^{\prime}\right)^{2}+\mu \cdot \frac{\partial_{\mathrm{u}}}{\partial \mathrm{x}}+\frac{1}{2}\left(\mathrm{~W}_{\mathrm{x}}^{\prime}\right)^{2}\right], \\
\mathrm{N}_{\mathrm{xy}}=\mathrm{G} \cdot \mathrm{h} \cdot\left(\frac{\partial_{\mathrm{u}}}{\partial \mathrm{y}}+\frac{\partial_{\mathrm{v}}}{\partial \mathrm{x}}+\frac{\partial_{\mathrm{w}}}{\partial \mathrm{x}} \cdot \frac{\partial_{\mathrm{w}}}{\partial \mathrm{y}}\right),
\end{gathered}
$$

it could be thought that by including nonlinear terms, as has been proposed by some authors [6], solely the use of the three last equations we could solve the problem. i.e. we could maintain it in a nonlinear calculation $\mathrm{u}=\mathrm{v}_{\mathrm{v}}=0 \forall \mathrm{x}, \mathrm{y}$. The solution found in this case is that which is included in the graph and indicated y dotted lines. It is evident that when we entered the field of large displacements $\mathrm{u} \neq 0$ and $\mathrm{v} \neq 0$ it is logical to expect, and this will be next revealed when the solution proposed by the system (94-98) once again shows the helpfulness of the theory proposed.

Characteristics: plate built-in on four sides

$$
\text { dimensions: } 4 \times 4 \times 0,25 \mathrm{~m}, \mathrm{E}=2 \cdot 10^{6} \mathrm{~T} / \mathrm{m}^{2}, \mu=0, \mathrm{D}=2604,17
$$

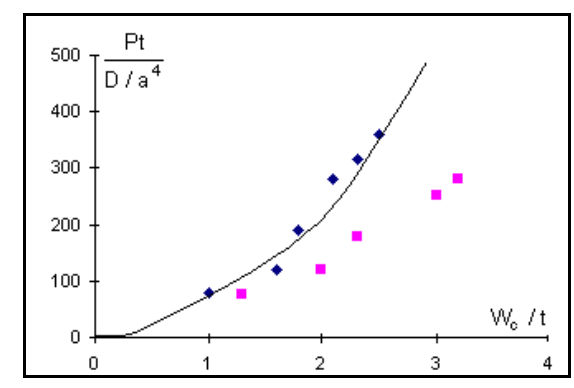

Figure 5.Solution Brebia \& Connor 1969

- Solution with 5 equations R-B D.F mesh $17 \times 17$ in a quarter of the plate.

- Solution with 3 equations R-B $(\mathrm{u}=\mathrm{v}=0)$ D.F. mesh $17 \times 17$ in a quarter of the plate. 


\section{CONCLUSIONS}

The most important conclusions, and those which have been revealed in the course of the work are:

1) That the system directly derived from the Bolle - Reisner theory is only applicable to the calculation of thick plates and that one of the equations originally proposed by Bolle Reisner is unsuitable.

2) That on proposing the equilibrium of the plate element in its deformed geometry, we have found a simplified and transformed system of 5 nonlinear differential equations (for linear studies these reduce to 3) which was valid to obtain general solutions in plate study, meaning that from there on it was possible to dispense with the classification of thick or thin plates.

3) The whole range of solutions being developed at present for thin plates is immediately transferable for use in the present context and, therefore, for obtaining general solutions in plate study.

\section{REFERENCES}

[1] Bazant, Stability of Structures. Oxford, 1991

[2] Bolle L., Contributión au problème linéaire de flexión d'une plaque e’lastique. B. T. de la Siusse Romaude, 1947.

[3] Brush D. and Almroth B.O., Buckling of bars, plates and shells. New York, 1975.

[4] Martinez, J.M. López R, "The non-linear calculation of rectangular projection and shallow shells using the finite differences method". Bulletin I.A.A.S. no 3,1994.

[5] Reissner E. "The effect of transverse shear deformation on the bending of elastic plates". Journal Applied Mechanic, 12, 69-77, 1945.

[6] Rekach V.G. Problemas de la Teoría de la Elasticidad,Editorial MIR,1978.

[7] Timoshenko S., Woinowski S. Teoría de Placas y Láminas, Urmo, Bilbao, Spain, 1970.

[8] Voyiaddjis G. Z. and Karamanlidis D. Advances in the Theory of Pates and Shells, Elsevier Science Publishers B.V., Amsterdam, The Netherlands, 1990.

[9] Zienkiewicz O. C., Taylor L.R. El Método de los Elementos Finitos, McGraw-Hill and CIMNE, Barcelona, Spain, 1994. 